\title{
CONFIABILIDADE E TRIBOLOGIA AUTOMOTIVA - UMA REVISÃO -
}

\author{
Marcos B.Garcia ${ }^{1}$, Carlos Mussato ${ }^{2}$ \\ ${ }^{1}$ Energy Plus Treinamentos \& Consultorias, UFABC \\ ${ }^{2}$ ZF do Brasil Ltda, UNICAMP
}

E-mails: $\underline{\text { marcos@ clickenergy.com.br, carlos.mussato@zf.com }}$

\section{RESUMO}

A escassez de petróleo e a busca por novas fontes de energia são hoje preocupações globais, principalmente no que tange a crescente demanda e as suas conseqüências para o aumento do consumo serão no futuro próximo os grandes desafios.

O trabalho apresenta algumas considerações básicas dos aspectos da tribologia do sistema powertrain típico, que inclui o motor, transmissão e os pneus, a partir de dados que determinam o destino da energia oriunda da queima do combustível. Estima-se que nos veículos de passeio aproximadamente $12 \%$ da energia avaliada encontram-se no contato dos pneus com o pavimento, enquanto que o motor e a transmissão contribuem com aproximadamente $60 \%$ e $5 \%$ respectivamente, das perdas mecânicas dissipada principalmente pelo atrito.

Grandes desafios de P\&D visam veículos mais compactos, utilizando novos lubrificantes e tecnologias de combustíveis associado ao aumento de potencia, da performance e consequientemente da redução nos níveis de emissões dos poluentes.

No entanto, busca-se a integração dos conceitos de engenharia juntamente com a ciência de superfícies, de modo que haja uma unificação dos sistemas automotivos, que somados aos avanços da modelagem, condição monitoramento e diagnósticos apresente resultados que indicam uma necessidade crescente de melhoria dos métodos para determinação da confiabilidade e estimativa do tempo de vida dos veículos, que aliados ao conhecimento da tribologia venha contribuir para a redução de perdas de energia, bem como atender as perspectivas globais no que tange regulamentação ambiental.

\section{INTRODUÇÃO}

Sob diversos aspectos, a confiabilidade de um produto tem impacto direto na satisfação do usuário, sendo um desses aspectos é a durabilidade. Lembrando que um produto menos confiável pode requerer intervenções mais freqüentes para reparos, cujos gastos podem anular a vantagem inicial de um valor mais baixo de aquisição. Mesmo que estes reparos sejam feitos durante o período de garantia, fato que ocorre em serviços de assistência técnica, causando transtornos e conseqüentes arranhões na marca do fabricante ${ }^{[1]}$.

O constante aumento dos requisitos pelo mercado, na busca por veículos com maior qualidade tem sido uma das exigências para os fabricantes automotivos. Entretanto, antes do inicio da produção são necessário testes que certifiquem a confiabilidade dos novos produtos, mas devido ao custo e limitação de tempo, pequenas quantidades de amostras destes produtos são avaliadas, resultando com isso, menores níveis de confiabilidade. 
O requisito 7.3.2 da norma ISO TS 16949, indica a entrada para projetos e/ou desenvolvimento, que deve-se determinada e registrada de acordo com os requisitos do produto $^{[2]}$, que incluem:

- Requisitos funcionais e de desempenho

- Requisitos legais e regulatórios aplicáveis

- Informação aplicável oriundas de projetos similares anteriores

- Quaisquer outros requisitos essenciais, como:

- Capabilidade, a relação entre a quantidade de peças conformes produzidas e o número total de peças fabricadas (PPM, Cpk, Cmk, etc).

- Confiabilidade, a probabilidade que um item (produto, processo, máquina, etc) possa ter boa performance continuamente, sem falha em um intervalo especifico sob determinadas condições.

$$
\mathrm{R}(\mathrm{t})=\frac{\mathrm{N}^{\mathrm{o}} \text { sucesso }}{\mathrm{N}^{\mathrm{o}} \text { total }}=\frac{\text { Ntotal }- \text { Nfalhas }}{\text { Ntotal }}=1-\text { Não Confiabilidade }
$$

- Manutenibilidade, probabilidade que o item possa ser mantido ou reparado para uma condição de operação especifica em um intervalo especifico quando a manutenção é realizada conforme procedimentos existentes.

- Disponibilidade, relação entre o tempo de operação do item e o tempo total.

A confiabilidade do produto é um fator que tem assumido cada vez mais importância para se avaliar a qualidade ao longo do ciclo de vida dos produtos. Principalmente em cenários de alta concorrência, onde os custos de produção são um diferencial decisivo para a competitividade dos produtos. O custo total do produto engloba tanto os custos de produção como custos decorrentes de pedidos de garantia. Para os clientes o custo de manutenção é um fator decisório para a compra deste bem de capital, como no caso dos veículos automotores.

A distribuição de energia de um veículo de passageiro em um ciclo de condução específica está representada pela Fig. 1. No ponto de vista do motor, apenas $25 \%$ da chamada energia útil a partir da energia total de entrada (capacidade energética do combustível) está disponível, sendo reduzida ainda mais devido às perdas pelas engrenagens, restando apenas $12 \%$ que vão estar disponíveis entre as rodas e o pavimento para conduzir o carro. Outras contribuições podem vir devido à diferentes condutores e condições de funcionamento, além das propriedades tribológicas que podem melhorar ainda mais a eficiência mecânica. 


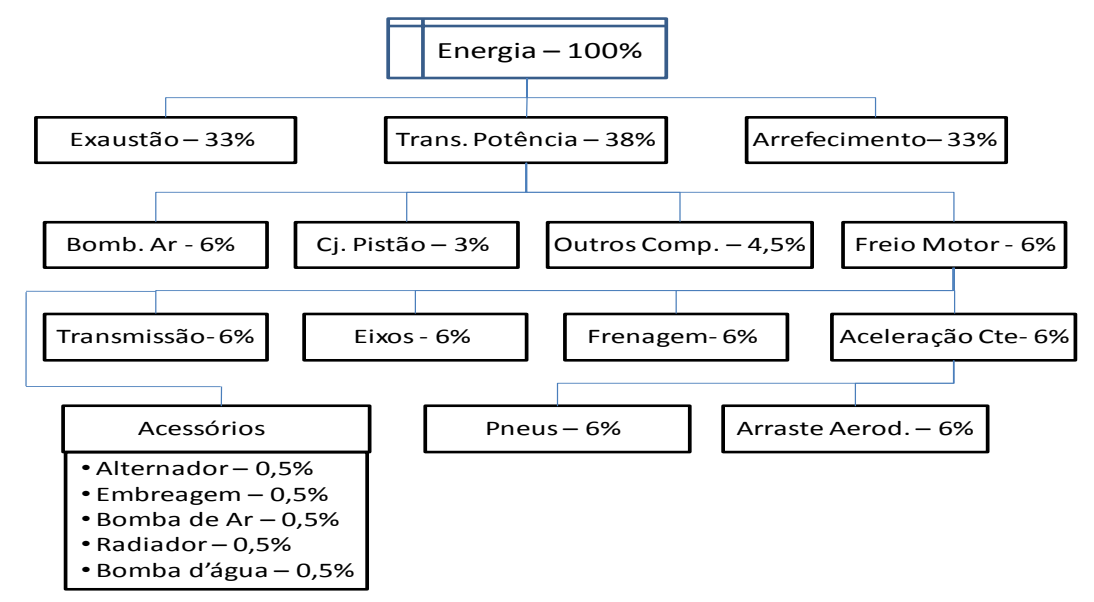

Figura 1 - Distribuição de energia em um veículo de passeio durante ciclo EPA city/highway (BARTZ, 1997)

Uma visão abrangente dos aspectos da tribologia do sistema powertrain típico, que inclui o motor, transmissão e os pneus, é feita a partir dos dados que determinam o destino da energia oriunda da combustão. O sistema propulsor e a transmissão contribuem com aproximadamente $60 \%$ e 5\%, respectivamente, das perdas mecânicas dissipadas principalmente pelo atrito.

\section{CONFIABILIDADE}

Todos os produtos têm uma vida útil limitada evidentemente, mas que deve-se buscar portanto uma maximização desta importante variável, através do uso da tecnologia e conhecimento específico aplicado aos conceitos de tribologia e confiabilidade ${ }^{[4]}$. Em um rigoroso estudo do ciclo de vida do produto, não se deve desconsiderar rigorosamente os seguintes fatores abaixo:

- Novos desenvolvimentos oferecendo melhoria da funcionalidade do componente ou sistema - Métodos eficientes e eficazes de produção para novos produtos

- Flutuações de demanda e tendências de estilos

- Atitudes e percepção dos consumidores

- Exigências legais e econômicas

- Política de mercado inadequada ou inapropriada

Uma das principais funções probabilísticas usadas para descrever estudos provenientes de testes de durabilidade é a função de confiabilidade, definida como a probabilidade de um produto desenvolver sua função sem falhar até um determinado tempo (t). A figura 2 apresenta a curva típica da função de confiabilidade para dois produtos, de marcas diferentes que desenvolvem a mesma função. 


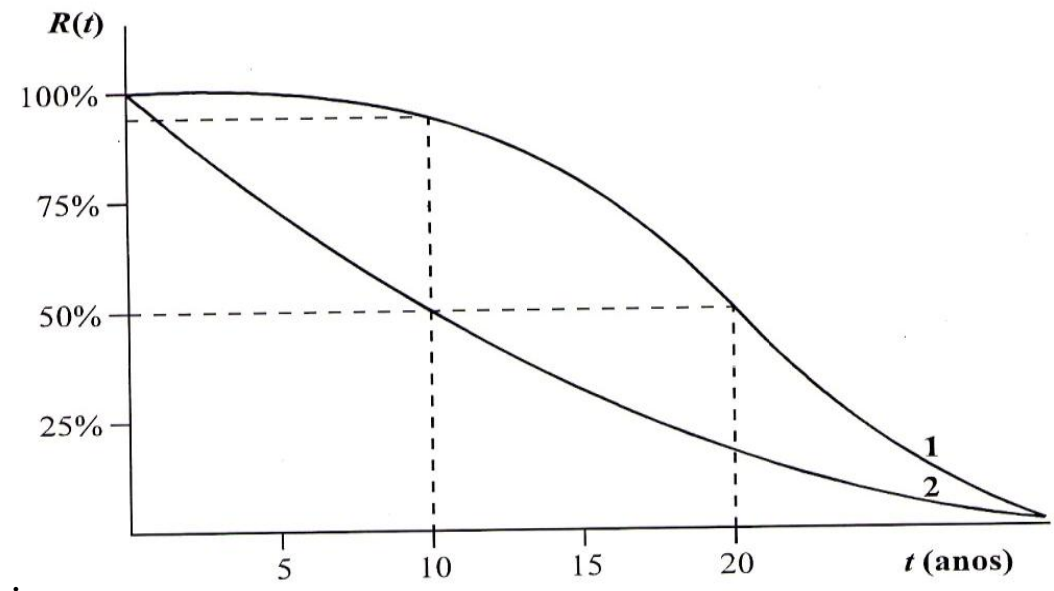

Figura 2 - Funções de Confiabilidade, R(t) para dois produtos (FREITAS, 1997)

Nota-se que o produto 1 apresenta uma durabilidade superior ao produto 2, onde $90 \%$ ainda estarão em operação com 10 anos de uso, enquanto que para o produto 2 apenas $50 \%$. A vida média (B50) do produto 1 é o dobro do produto 2, ou seja, 20 anos.

As situações estudadas em confiabilidade envolvem o tempo até a ocorrência de um evento interessante. Estes eventos são, na maioria dos casos, indesejáveis e usualmente chamado de falha. Em algumas situações a definição de falha pode assumir termos ambíguos, ou seja, as mais usuais são chamadas de catastrófica. Como os sistemas mecânicos reparáveis degradam com o tempo, algumas vezes existem apenas uma linha divisória entre atender a sua função ou falhar. A taxa de falha $\mathrm{F}(\mathrm{t})$ de um sistema mecânicos reparáveis indica os seguintes comportamentos que estão representados pela figura 3 .

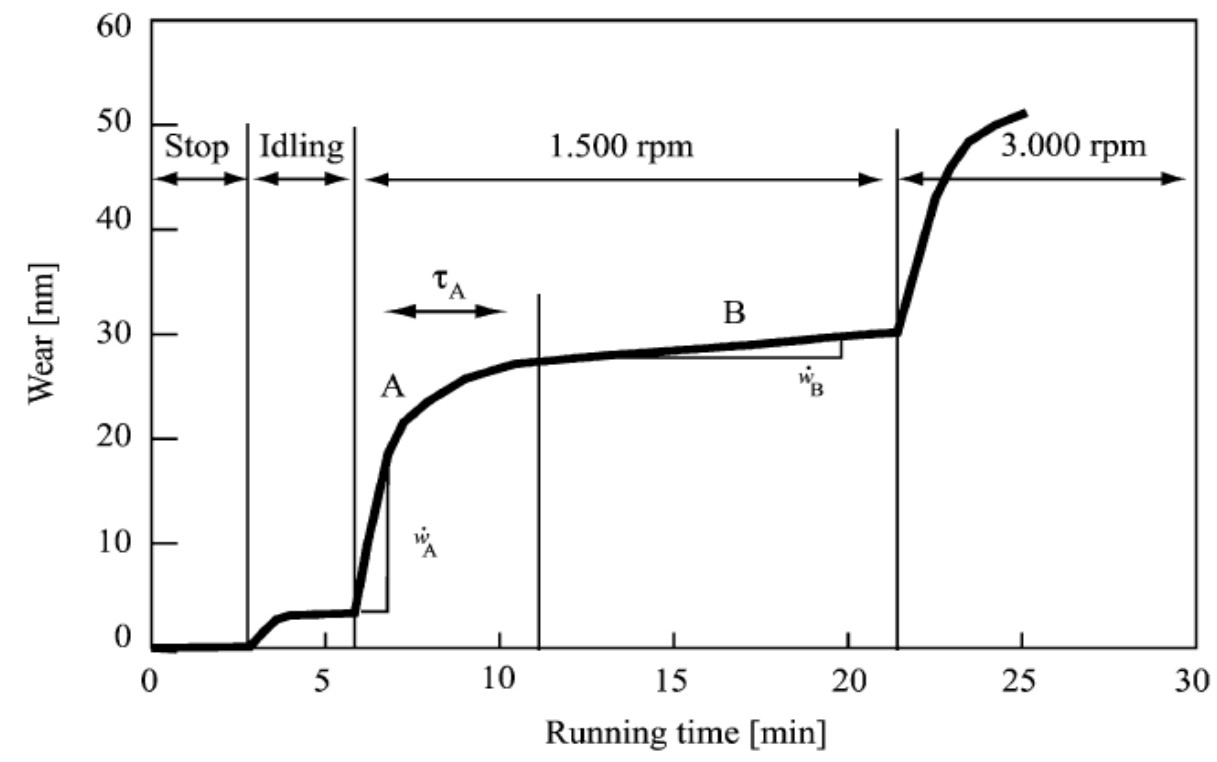

Figura 3 - Curva típica de desgaste metálico em sistemas mecânicos para o período de running -in (STOLARSKI, 2000) 
- A maioria dos produtos começará suas vidas com a alta taxa de falhas e depois apresentarão uma redução a partir de um determinado ponto;

- A taxa de falha então se estabiliza e se mantém constante durante a vida útil do produto;

- Com o decorrer do tempo o produto degrada (desgaste, fadiga, corrosão, contaminação do lubrificante, etc) e a taxa de falha começa a aumentar rapidamente com o tempo.

\section{TRIBOLOGIA}

A definição da norma alemã de atrito conclui que um dos efeitos do atrito é o desgaste. Este raciocínio parece lógico e convincente no caso de contato entre dois corpos. Nestes casos o desgaste pode ser relacionado à ação da força normal e da força tangencial resultante da força de atrito ${ }^{[5]}$.

As condições de desgaste e atrito do tribosistema são determinadas por alguns parâmetros, nos quais a predominância de um ou de outro dependem das condições de funcionamento (carga, velocidade e temperatura), das condições de interface (meio triboquímico como a lubrificação, subprodutos da combustão e gradientes de temperatura) e das condições estruturais (características geométricas, materiais e tratamentos superficiais) do par tribológico ou triboelementos.

O exemplo clássico é a influencia da carga normal e da velocidade sobre os regimes de desgaste, pois os mesmos influem na taxa de deformação plástica e temperatura induzida por atrito nas superfícies, podendo modificar a constituição da microestrutura e também alterar a propriedade mecânica das superfícies, ou ainda, interferir na taxa de oxidação superficial quando submetido à determinadas temperaturas ${ }^{[6]}$.

A figura 4 apresenta esquematicamente o comportamento típico da degradação para diferentes mecanismos de desgaste ${ }^{[8]}$.

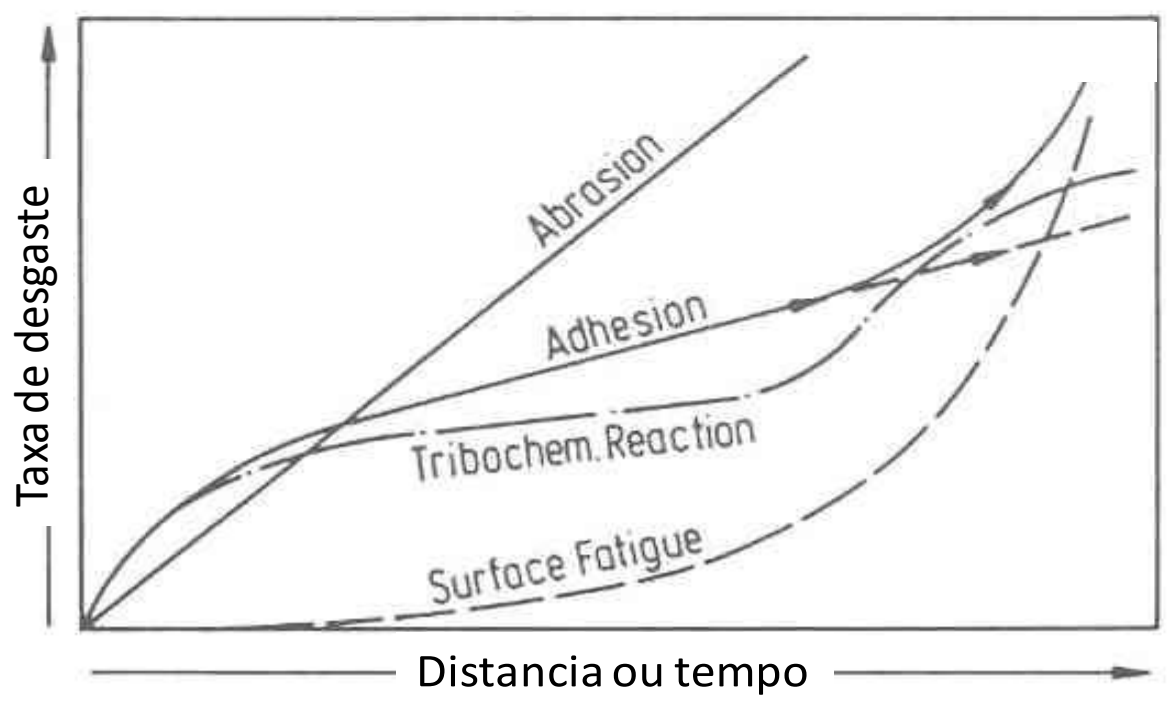

Figura 4 - Mecanismos de desgaste em função do tempo ou distancia de deslizamento (Zum Gahr, 1987) 
O atrito é o objeto de estudo e de desenvolvimento de novas tecnologias de revestimentos metálicos e cerâmicos, e de acabamentos superficiais de extrema precisão e baixíssima rugosidade. Grandes inovações e rápidas modificações se conseguem, sem as premissas acima, mas quando estas são impostas pelas condições de mercado e exigências ambientais, a tribologia é aplicada como chave mestre das soluções com resultados significativamente melhores que a condição inicial de projeto. Melhorar desempenho e economia, demandam não somente tecnologia e conhecimento técnico científico avançado, como também de uma fabricação altamente estável e confiável.

\section{MOTOR DE COMBUSTÃO INTERNA}

De forma subjetiva, a proporção de perda total por atrito nos motores à combustão está direcionada em $40 \%$ para o conjunto do pistão. Os conjuntos envolvendo pistão, válvulas e mancais são submetidos a diversas condições tribológicas durante os ciclos de operação, e em diferentes modos de lubrificação que podem ser compreendidos através da representação do diagrama de Stribeck modificado (Figura 5) ${ }^{[7]}$.

As perdas por atrito em sistemas lubrificados são de aproximadamente $2 / 3$ para o regime hidrodinâmico e 1/3 para o misto, que envolve o elasto-hidrodinâmico e o boundary. Neste último, as condições do regime de lubrificação e os mecanismos de desgaste ocorrem em escala atômica, ainda pouco explorado e carente de estudos sobre as reações físicoquímicas que ocorrem na superfície de contato ${ }^{[3]}$.

A durabilidade do par tribológico anel-cilindro talvez seja um dos fatores que determinam a vida efetiva dos motores, e as condições a que estão submetidos os anéis de pistão torna este o componente mais complexo da câmara de combustão interna, devido as altas solicitações na região do PMS (carga, velocidade e temperatura) e pela variação no suprimento de óleo lubrificante, principalmente do anel de compressão alojado no primeiro canalete do pistão.

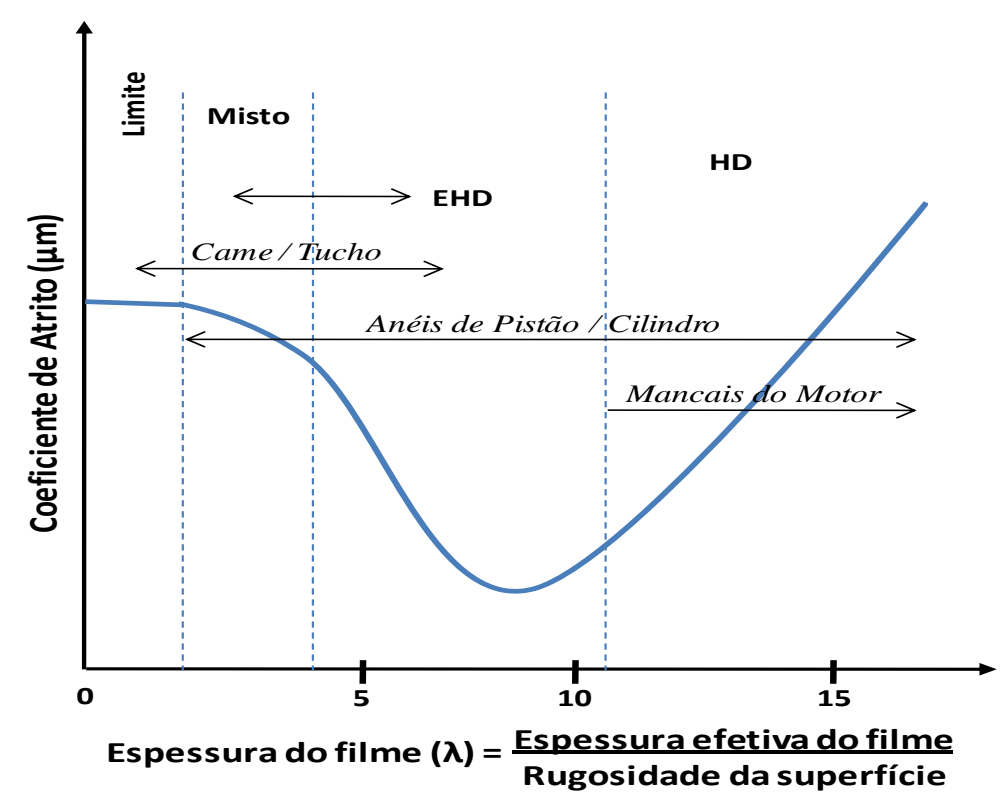

Figura 5 - Diagrama de Stribeck modificado. Variação do coeficiente de atrito com a espessura do filme lubrificante para alguns tribo-sistemas de motores automotivos (TERHECI, 1995) 
Até a Segunda Guerra Mundial, os anéis de compressão não eram revestidos, porém, com a necessidade de maior resistência dos motores no deserto da África iniciou-se a aplicação de revestimento a base de cromo através de processos eletrolíticos, com uma satisfatória resistência ao desgaste abrasivo e corrosivo ${ }^{[7]}$, mas quando submetido a condições críticas de cargas e temperatura apresentava baixa resistência ao Scuffing (um tipo de desgaste adesivo), devido ao aumento localizado de pressão nas asperezas, com a ausência de lubrificação pode ocorrer uma adesão de materiais por micro soldagem e a ruptura desta região, assim como a transferência de material de uma superfície para a outra. Este tipo de falha tem maior incidência na fase de amaciamento do motor.

No final da década de 50, com a ampliação das vias de pavimentação em escala mundial e com a nova geração de motores automotivos, iniciou-se a fabricação de anéis de primeiro canalete com revestimento de molibdênio aplicado por aspersão térmica com chama ou plasma. A elevada resistência ao scuffing do revestimento de molibdênio é atribuída ao seu elevado ponto de fusão, a estrutura porosa e pelo efeito lubrificante do óxido de molibdênio. A estrutura porosa resultante da aspersão do metal funciona como reservatório de óleo lubrificante melhorando principalmente o desempenho nas condições mais críticas de operação.

Os anéis de pistão são partes metálicas geralmente fabricadas com ferro fundido cinzento ou nodular com um tratamento superficial a base de molibdênio na região de contato com o cilindro que confere uma maior resistência ao desgaste.

As novas tendências de projetos e materiais para anéis de pistão são determinadas em todo o mundo pela necessidade do mercado. O produto consagrado em alguns países e em andamento em outros utilizam aço inoxidável com alto teor de cromo, que atribui melhores características funcionais e satisfatória resposta ao processo de nitretação principalmente do aço com $18 \%$ de cromo, assim como o aço com $13 \%$ de cromo que também confere boas características na camada nitretada e um baixo custo de produção. Nos Estados Unidos e GrãBretanha dão preferência para o aço com $13 \%$ de cromo, enquanto que no Japão e na Alemanha predomina o aço com 18\% de cromo; o mesmo vem ocorrendo na América Latina .

Para os tratamentos de superfície, metalização por aspersão térmica (Mo), nitretação gasosa (Nitret) e eletrodeposição (CrComp) foram atribuídos após 500 horas de ensaio em dinametro, que a menor resistência ao desgaste foi determinada para a maior variação da distância entre pontas dos anéis de pistão, da mesma forma para a porcentagem de área espelhada da camisa de cilindro ${ }^{[6]}$, indicados na figura 6.

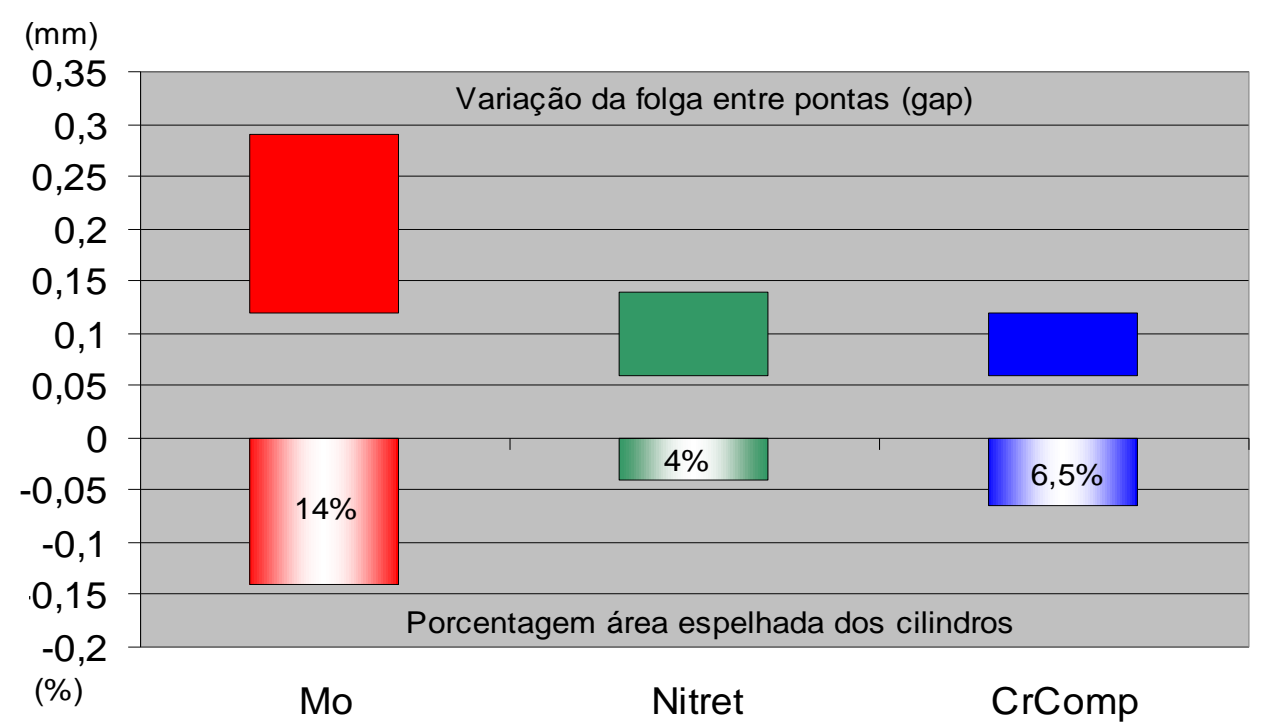

Figura 6 - Variação da folga entre pontas e porcentagem de área espelhada no cilindro 


\section{TRANSMISSÃO}

Esta parte do powertrain é responsável pela transferência e escalonamento do torque do motor através das marchas de velocidades projetadas para atender à uma relação de capacidade de rampa, velocidade final e consumo de combustível. A perda energética deste agregado pode chegar a aproximadamente 5\%, levando-se em conta as transmissões de movimentos para os eixos traseiros.

Devido às más condições de estradas e topografia crítica de regiões onde os veículos automotores são utilizados, torna-se um desafio reduzir os atritos dinâmicos nos contatos metálicos importantes como os denteamentos e sistemas de mudança de marchas, de forma a garantir que haverá escalonamento de torque suficiente para bom desempenho do veículo, bem como que haja significante melhoria no rendimento da transmissão, ou na sua capacidade de diminuir a perda energética total proveniente da queima combustível no motor.

A tribologia é aplicada nas uniões metálicas com deslizamentos cruzados, rotativos e rolantes. Uma das maiores fontes de particulado metálico que se desprende dos componentes da transmissão e permanecem em suspensão no lubrificante, ocorre nos cones dos corpos de acoplamento do conjunto sincronizado. Aplica-se nesta região, um acabamento superficial retificado com rugosidades da ordem de Rz4. Porém somente esta característica não garantiria a frenagem ideal do conjunto para o engrenamento sem interferências. Para contribuir com a condição tribológica ideal para menor desgaste, são utilizados anéis sincronizados com aplicações de camada de carbono ou molibdênio. A figura 7 demonstra a influência dos revestimentos nos flancos dos dentes submetidos à altas pressões de contato [ ${ }^{16]}$.

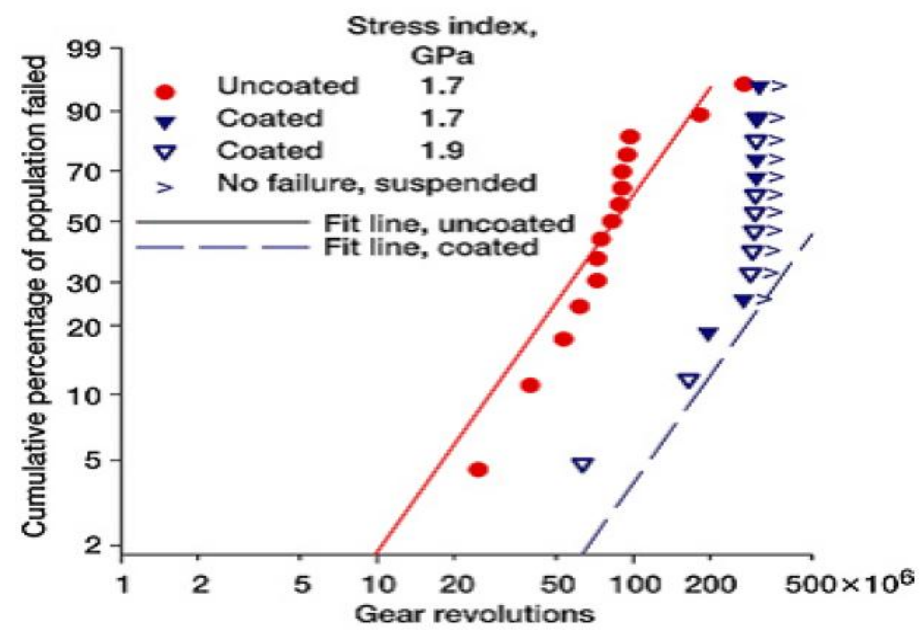

Figura 7 - Testes acelerados para verificação de pitting

Aliado à estas combinações de materiais e revestimentos, faz-se necessário o uso de lubrificantes dedicados à condição tribológica projetada. Estes lubrificantes terão a responsabilidade de reduzir as temperaturas entre os flancos dos dentes das engrenagens, de permitir expulsão eficiente do filme de óleo para o momento da frenagem do conjunto sincronizado e de manter os particulados metálicos e não metálicos em suspensão para fora das áreas de contatos dos rolamentos e dentados.

Nos veículos de passeio, as transmissões possuem escalonamento de marchas com menores reduções e portanto a condição tribológica exigida é voltada à redução de ruído, que ocorre em função da frequência de giro de cada par engrenado. Este requisito é fundamental nesta categoria de veículos porque o motorista pode identificar o problema e proceder o envio 
à garantia, podendo ser gerados custos de reposição de peças. Por isso é importante seguir o manual dos veículos para com as recomendações de manutenção e dirigibilidade ${ }^{[17]}$.

A tribologia passa a se tornar ainda mais influente no desempenho e vida útil de transmissões, quando essas são de comutação de marchas automáticas. Neste caso, o requisito principal é o acabamento superficial metálico, o uso de materiais sinterizados e temperados, e a combinação entre um lubrificante com baixíssimos valores de viscosidade e sujidade ou particulado metálico, pois a troca de marchas ocorre por intermédio de um conversor de torque, que também tem atuação hidrodinâmica ${ }^{[18]}$.

Novos projetos de transmissões otimizam o torque do motor através de um escalonamento de marchas com baixo RPM em velocidades altas, como por exemplo cerca de $2000 \mathrm{RPM}$ à $120 \mathrm{Km} / \mathrm{h}$. Isso contribui significativamente para a economia de combustível e para a preservação da vida útil da transmissão. A utilização de tecnologias de embreagens duplas pode tornar o desempenho e economia de combustível ainda melhor. No caso de veículos de competição, se faz o uso de embreagens com revestimento cera-metálico, que absorve com eficiência o gradiente de calor gerado por partidas bruscas em altos giros ${ }^{[19]}$.

A evolução das transmissões no tocante à economia de combustível está na tecnologia de e projeto híbrido, onde parte da energia consumida pela transmissão é utilizada por meio de uma fonte elétrica ou bateria. Consiste, portanto no aproveitamento da inércia do movimento inicial conseguido com o conjunto mecânico convencional ou torsionado pelo motor à combustão. Se este projeto beneficia a economia de combustível, exige ainda mais da condição tribológica dos componentes de interface dos sistemas como coolers e placas eletrônicas de comando. Os materiais, seus acabamentos e o lubrificante utilizado, devem ter perfeita harmonia para com os selantes e materiais borracha, evitando-se manutenções precoces e sempre onerosas ao proprietário do veículo[20].

\section{PNEUS}

Um componente importante para a condução, conforto e segurança veicular, atuando como interface entre o veiculo e a pista, sendo projetado para suportar e transmitir forças em diversas condições operacionais. Aceleração e desaceleração, forças laterais, irregularidades da pista e impacto são algumas condições dinâmicas as quais o pneu está submetido. É uma das poucas estruturas mecânica sujeita a grandes deflexões e deformações, confeccionados com materiais compósitos anisotrópicos, sendo a borracha seu principal componente ${ }^{[13]}$.

Ao longo de sua utilização o pneu apresenta desgaste, principalmente em sua banda de rodagem, sua capacidade em demonstrar maior durabilidade está diretamente ligada ao modo como o componente dessa região resiste a diferentes condições de uso.

A figura 8 indica as principais características dos compostos de borracha Natural (NR), Estireno Butadieno (SBR), Poli Butadieno (BR) e Poli Isopreno (IR). 


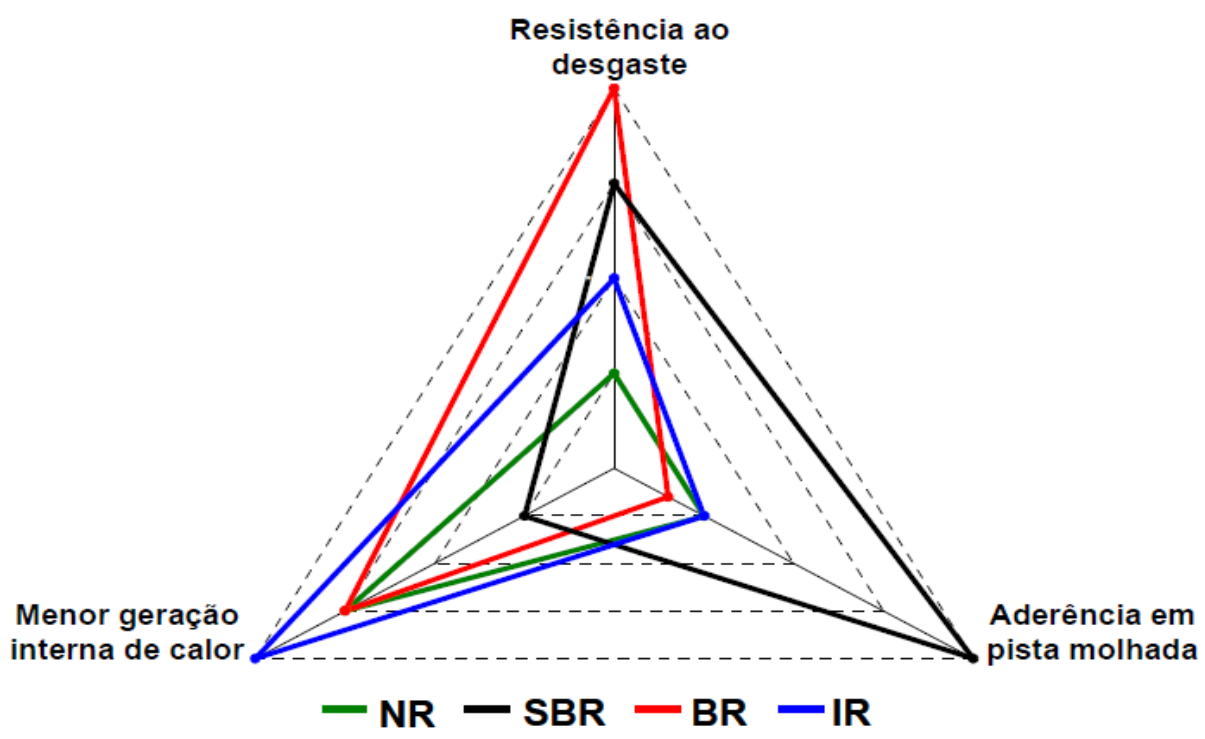

Figura 7 - Principais características dos compostos de borracha

Utilização de uma carga em um composto depende das propriedades exigidas, que entre outras podem seu aumento de dureza, rigidez, resistência à abrasão ou redução de custo. As cargas destinadas a melhora das propriedades mecânicas são denominadas reforçantes (Negro de fumo ou Sílica). Em engenharia de transporte, o pavimento é a camada constituída por um ou mais materiais que se coloca sobre o terreno de modo a aumentar sua resistência e garantir a mobilidade de pessoas e veículos. No Brasil, a maioria dos pavimentos utiliza os revestimentos asfálticos, que são os usinados à quente ou a frio, os tratamentos superficiais ou os microrevestimentos à frio e lamas asfálticas ${ }^{[14]}$.

Os tratamentos superficiais são executados por aplicações sucessivas de camadas de ligante asfáltico e camada de agregados de dimensões similares. O tratamento pode ser simples, no qual há uma camada de ligante seguida de uma camada de agregados (TSS) ou dupla (TSD), que consiste na aplicação de duas camadas de ligante asfáltico e duas camadas de agregados, sendo a primeira de agregados graúdos e a segunda mais miúda. A figura 9 apresenta uma representação dos tratamentos superficiais.

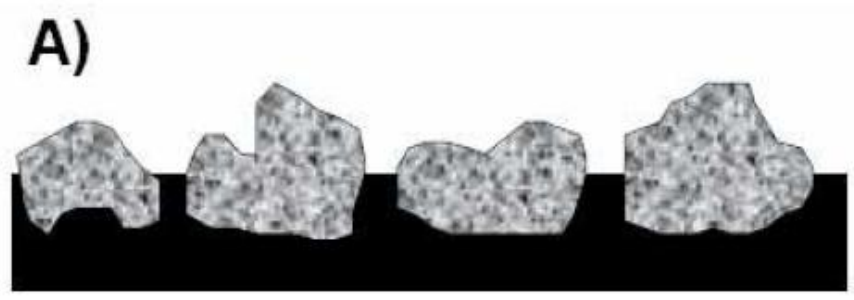

B)

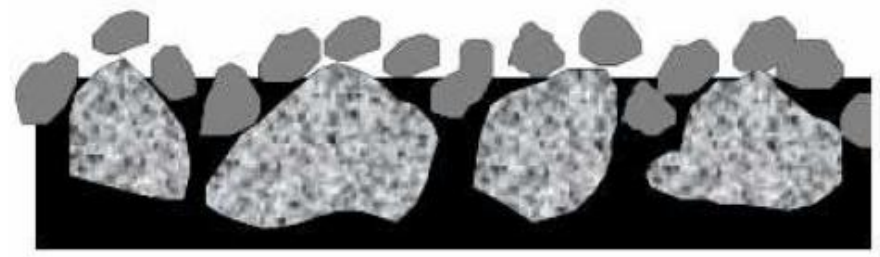

Figura 9 - Esquema de tratamentos superficiais asfálticos:

(A) Simples; (B) Duplo (APS, 2006) 


\title{
CONSIDERAÇÕES FINAIS
}

- A demanda crescente por energia e as consequiências no aumento de consumo serão nos próximos anos um grande desafio para a sustentabilidade do planeta. A politização aliada ao consumo e aos elevados preços do petróleo poderão tornar o sistema altamente vulnerável;

- A crescente necessidade de melhorias nos métodos para determinação da confiabilidade e estimativa do tempo de vida dos veículos, aliados ao conhecimento da tribologia;

- O grande desafio na busca pela redução do atrito em componentes veiculares submetidos a movimentos relativos estão voltados principalmente para os sistemas motor e de transmissão, e seus respectivos regimes de lubrificação.

- A adequação das características de cada parâmetro, visando a melhoria no comportamento dos pares tribológicos durante o período de amaciamento e ao longo da vida do motor, vem utilizando testes acelerados ou de bancada como uma sugestão rápida e de baixo custo no desenvolvimento de novos componentes.

- A utilização de aços com ligas especiais e revestimentos metálicos com redutores de atrito superficiais, associadas à uma microgeometria de contato otimizada, têm sido o diferencial de desempenho e qualidade dos componentes, através da redução do desgaste e atrito.

- O estudo do fenômeno de atrito pode alcançar saltos importantes no conhecimento, um exemplo disso é a nanotecnologia, onde os componentes apresentam uma elevada relação área/volume.

\begin{abstract}
AUTOMOTIVE RELIABILITY AND TRIBOLOGY - A REVIEW

The lack of oil and the quest for new energy sources today are global concerns, especially regarding the growing demand and its consequences for the growth of consumption in the near future will be the major challenges.

The paper presents a comprehensive overview of the tribological aspects of typical powertrain system, including the engine, transmission and tires, from data that determine the destination of the energy from the burning fuel. It is estimated that passenger vehicles in approximately $12 \%$ of the energy are evaluated in tire contact with the roadway, whereas the engine and transmission systems contribute about $60 \%$ and $5 \%$, respectively, of mechanical losses mainly dissipated by friction.

Great challenges for R \& D aimed at more compact vehicles, using new lubricants and fuels technologies associated with increased power, performance and consequently the reduction in emission levels of pollutants.

However, it conjecture to integrate engineering concepts along with the surfaces science, so that there is a unification of automotive systems, which added to the advances in modeling, condition monitoring and diagnostics has presented results that indicate a growing need for improvement methods for determining the reliability and estimate the lifetime of the vehicles, which combined with the knowledge of tribology are contributing to the reduction of energy losses, as well as serving global perspectives regarding environmental regulations.
\end{abstract}




\section{REFERÊNCIAS}

[1] FREITAS, M.A.; COLOSIMO, E.A., Confiabilidade: Análise de Tempo de Falha e Testes de Vida Acelerados, TQC Série Ferramentas da Qualidade, vol.12, 1997

[2] OMNEX, Implementação da ISO TS 16949:2002

[3] BARTZ, W.J., Viscosity Influence on Friction Condition and Fuel Economy of Automobiles - Some Basic Considerations, SAE Technical Paper Series 972858, International Fuels \& Lubricating Meeting \& Exposition, Tulsa, Oklahoma, 1997

[4] STOLARSKI, T.A., Tribology in Machine Design. Oxford, 2000.

[5] UETZ, H., Abrasion und Erosion, Grundlagen Betriebliche Erfahrungen Verminderung, Berlin: Carl Hansen Verlag, p.829, 1986

Ed.Philadelphia: ASM International, 1995

[6] GARCIA, M.B.; AMBRÓZIO Fo , F.; VATAVUK, J.;Wear Mechanisms Behavior of Different Surface Treatment Piston Rings, São Paulo SAE 2003-01-3589

[7] SHEN, Q., Development of Material Surface Engineering to Reduce the Friction and Wear of the Piston Ring, SAE 970821, International Congress \& Exposition , 1997

[8]ZUM GAHR, K.H., Microstructure and Wear of Materials. Amsterdam: Elsevier, 1987

[9] GARCIA, M.B.; Anel de pistão e processo de obtenção, patente INPI PI9702729-4a depositada em 1997

[10] TERHECI, M.; MANORY, R.R.; HENSLER, J.H. The friction and wear of automotive gray cast iron under dry sliding condition. Wear, v. 185, p. 119-124, 1995.

[11] BLAU, P. J. Metals Handbook v. 18: Friction Lubrication and Wear Technology.

[12] DEVLIN, M.T.; TURNER, T.T., Wear prevention by phosphorus species that form thin tribofilms, Parma, Itália, 2006.

[13] COSTA, A.L.A, Caracterização do comportamento vibracional do sistema pneususpensão e sua correlação com o desgaste irregular verificado em pneus dianteiros de veículos comerciais, Poli USP, 2007

[14] CARDOSO, F.A., Estudo do desempenho dos compostos de borracha utilizados na fabricação da banda de rodagem dos pneus automotivos em função dos pavimentos das rodovias. Poli USP, São Paulo, 2010

[15] SCHERGE,M.; PÖHLMANN, K., Wear measurement using radionuclide-technique (RNT), Karlsruhe, Germany, 2003

[16] PENNEL, J.A., Slow speed wear of spur and helical gearing. University of Newcastle upon Tyne, Abril, 1989.

[17] JAO, T.C.; DEVLIN, M.T., Influence of Surface Roughness on Gear Pitting Behavior. Gear Technology, Junho, 2006.

[18] SCHOLZ, C., Low friction slip-rolling contacts - Influences of alternative steels, high performance thin film coatings and lubricants. Berlin, 2013.

[19] DeGONIA,D.; HEWETTE, C., Technology Required in Modern Automotive Gear Oils. Afton Chemical, Japan, 2006.

[20] SHAKHVOROSTOV, D.; PYZALLA, A., Mechanical Proprieties of Tribologically Modified Nano-layers. Stuttgart, Germany, Dezembro, 2004.

[21] HARALD, N.; LECHNER, G., Fundamentals, Selection, Design and Application. Automotive Transmissions. Berlin, Germany, 1999.

[22] LENZ, M.; MILLER, W., Drive. The ZF Magazine, Marz, 2009. 